\title{
Application of IBA on in vitro and ex vitro rooting microcutting of Lavandula angustifolia Miller
}

\author{
Marília Pereira Machado $^{1, *}$, Cícero Deschamps ${ }^{2}$, Luiz Antonio Biasi ${ }^{2}$
}

\begin{abstract}
Rooting in vitro increases the cost of production of plants for the micropropagation of plants, because plants need another phase of development, and the use of culture medium plus growth regulators, burdening the process. The $e x$ vitro rooting for reducing the difficulties associated with survival the acclimatization and reduce production costs. The aim was to promote the in vitro and ex vitro rooting of micropropagated microcuttings of Lavandula angustifolia. Rooting in vitro promoted with concentrations of the IBA $0,0.5,1.0$ and $2.0 \mu \mathrm{M}$ were applied. Concentrations of $0,2.5,5.0$ and $10.0 \mathrm{mM}$ of IBA were applied on $2.0 \mathrm{~cm}$ and $4.0 \mathrm{~cm}$ in length microcuttings. With the application of IBA microcuttings in vitro decreased the number of roots, root length and rooting percentage. The better result obtained was $47.3 \%$ rooting with the control. $4.0 \mathrm{~cm}$ microcutting under effect of $5.0 \mathrm{mM}$ IBA recorded the highest percentage of rooting and survival of ex vitro microcutting. Analyses showed anatomical connection between the adventitious roots and the vascular system of the microcuttings, not being observed the formation of callus. It was concluded that the ex vitro rooting of microcutting of $L$. angustifolia is more efficient than in vitro rooting, producing a higher rooting percentage (85\%) and survival $(80 \%)$ using microcutting of $4.0 \mathrm{~cm}$, treated with $5.0 \mathrm{mM}$ IBA.
\end{abstract}

Key words: Lavender, adventitious root, micropropagation, survival

\section{Aplicação de ácido indolbutírico para o enraizamento in vitro e ex vitro de microestacas de Lavandula angustifolia}

\begin{abstract}
RESUMO
O enraizamento in vitro aumenta o custo de produção de plantas via micropropagação, pois as plantas necessitam de mais uma fase de desenvolvimento, além do uso de meio de cultura acrescido de reguladores vegetais, sendo que no enraizamento ex vitro há redução das dificuldades associadas à sobrevivência na aclimatização e a redução dos custos de produção $\mathrm{O}$ objetivo deste trabalho foi avaliar o enraizamento in vitro e ex vitro de microestacas de Lavandula angustifolia. Para o enraizamento in vitro foram aplicadas concentrações de 0;0,5; 1,0 e 2,0 $\mu \mathrm{M}$ de AIB, utilizando-se microestacas com 1,0 cm de comprimento. Para o enraizamento ex vitro concentrações de $0 ; 2,5 ; 5,0$ e $10,0 \mathrm{mM}$ de AIB, foram aplicadas às microestacas de $2,0 \mathrm{~cm}$ e 4,0 cm de comprimento. Com a aplicação de AIB nas microestacas in vitro houve redução do número de raízes, comprimento das raízes e porcentagem de enraizamento, sendo o melhor resultado obtido com o controle, 47,3\% de enraizamento. Microestacas de 4,0 cm de comprimento tratadas com 5,0 mM de AIB, apresentaram maior porcentagem de enraizamento e sobrevivência ex vitro. Análises anatômicas demonstraram conexão entre as raízes adventícias e o sistema vascular das microestacas enraizadas ex vitro, não sendo observada a formação de calo. Concluiu-se que o enraizamento ex vitro de microestacas de $L$. angustifolia micropropagada é mais eficiente do que o enraizamento in vitro, produzindo maior taxa de enraizamento ( $85 \%)$ e sobrevivência ex vitro $(80 \%)$ utilizando microestacas com $4,0 \mathrm{~cm}$ de comprimento, tratadas com 5,0 mM de AIB.

Palavras-chave: Lavanda, raízes adventícias, micropropagação, sobrevivência

\footnotetext{
*Autora para correspondência.

1,* Pós-Doutoranda, Universidade Federal do Paraná; Curitiba-Brasil,ma_rilia10@hotmail.com

${ }^{2}$ Professor Associado, Universidade Federal do Paraná; Curitiba - Brasil, deschamps@ufpr.br, biasi.ufpr@gmail.com
} 


\section{INTRODUÇÃO}

A Lavandula angustifolia Miller é uma planta de reconhecida importância devido ao óleo essencial contido em suas flores e folhas, que é usado para a fabricação de remédios, pomadas, perfumes, cosméticos e produtos de limpeza. O óleo essencial da lavanda possui propriedades antiséptica, antinflamatória, analgésica, antifúngica e bactericida, pois é rico em terpenos (Kreis e Mosandl, 1992; Sugawara et al., 1998; Ghelardini et al., 1999; Flores et al., 2005).

Pertencente à família Lamiaceae, a espécie $L$. angustifolia é um arbusto lenhoso nativo da Europa, que pode ser propagado a partir de sementes ou vegetativamente (Upson, 2002). Para a obtenção de plantas homogêneas a propagação vegetativa é a mais recomendada. Porém, uma limitação que pode ser encontrada na produção de mudas de L. angustifolia pelo método usual de estaquia é a baixa capacidade de enraizamento das estacas (Biasi e Deschamps, 2009). A micropropagação por rejuvenescer o material vegetativo, promove a retomada da capacidade de enraizamento e vigor de crescimento, podendo ser utilizada como um processo inicial para a produção de microestacas (Schuch et al., 2007), e posterior enraizamento ex vitro com simultânea aclimatização (George e Sherrington, 1984). Apesar das vantagens da micropropagação, esta técnica apresenta custo elevado e a eliminação da etapa de enraizamento in vitro é desejável do ponto de vista econômico (Yan et al., 2010), além de melhorar a qualidade do sistema radicial formado, uma vez que as raízes produzidas in vitro são consideradas frágeis e pouco funcionais (Pierik,1990), devido à incompleta conexão vascular entre a parte aérea e a raiz, conforme demonstrado em mudas de couve-flor enraizadas in vitro (Grout e Aston, 1977). Embora, tanto o enraizamento in vitro como ex vitro apresentaram perfeita conexão vascular entre as raízes adventícias e o câmbio vascular de Eucalyptus benthamii (Brondani et al., 2012).

Em plantas de eucalipto a técnica da microestaquia foi empregada para explorar ao máximo a juvenilidade dos propágulos vegetativos e maximizar o enraizamento das microestacas no processo de propagação clonal (Xavier et al., 2001). A microestaquia também vem sendo estudada como alternativa para a produção de mudas de diversas espécies de plantas medicinais e aromáticas, como Mentha piperita (Sunandakumari et al., 2004), Siratia grosvenorii
(Yan et al., 2010), Rotula aquatica (Martin, 2003a), Wedelia chinensis (Martin et al., 2003b), entre outras. Contudo, há poucas informações a respeito da utilização dessa técnica para $L$. angustifolia.

Assim como na estaquia convencional, a microestaquia é controlada por diversos fatores endógenos e exógenos. Em diferentes espécies foi demonstrado que a eficiência do enraizamento de microestacas é fortemente influenciada pelo tamanho inicial dos propágulos (Xu et al., 2008; Yan et al., 2010). Além disso, a aplicação exógena de auxina favorece o enraizamento ex vitro de microestacas de diferentes espécies (Karhu, 1997; Martin, 2003b; Xu et al., 2008; Yan et al., 2010). A auxina mais utilizada para a indução de enraizamento de propágulos é o ácido indolbutírico (AIB). Machado et al. (2011) reportaram eficiência da técnica de microestaquia aplicada a propagação de L. angustifolia utilizando microestacas de $4,0 \mathrm{~cm}$ de comprimento e aplicando auxina via talco. Porém, não é conhecido o efeito de microestacas menores e da aplicação convencional do AIB, via solução.

Devido à importância da fase de enraizamento na micropropagação, o objetivo do presente trabalho foi avaliar o enraizamento in vitro e ex vitro de microestacas de L. angustifolia tratadas com AIB.

\section{MATERIAL E MÉTODO \\ Produção de brotações in vitro}

Ápices caulinares foram coletados de planta matriz adulta (dois anos) de L. angustifolia cv. Provence Blue (proveniente de semente comercial importada da França) mantida em casa-de-vegetação. Os explantes passaram por um processo de assepsia em fungicida Cercobin ${ }^{\circledR}(2 \%)$ por 40 minutos, álcool $70 \%$ por 20 segundos, hipoclorito de sódio (1\%) mais Tween $20(0,2 \%)$ por 20 minutos e três lavagens em água destilada e esterilizada. Após a assepsia, foram retiradas as folhas dos ápices caulinares até que atingissem aproximadamente $5,0 \mathrm{mmm}$ de comprimento, e em seguida foram cultivados em meio de cultura MS (Murashige e Skoog, 1962), $100 \mathrm{mg} \mathrm{L}^{-1}$ de mio inositol, $30 \mathrm{~g} \mathrm{~L}^{-1}$ de sacarose, $0,5 \quad \mu \mathrm{M}$ de BAP (6benzilaminopurina) e $6 \mathrm{~g} \mathrm{~L}^{-1}$ de ágar Vetec ${ }^{\circledR}$, por um período de 30 dias em sala climatizada, com temperatura de $25 \pm 2^{\circ} \mathrm{C}$, densidade de fluxo de fótons de $40 \mu \mathrm{mol} \mathrm{m} \mathrm{m}^{-2} \mathrm{~s}^{-1}$ e fotoperíodo de 16 horas. Após o cultivo inicial, os ápices caulinares regenerados foram transferidos para o meio descrito anteriormente, e cinco subcultivos foram 
realizados em intervalos de 40 dias. Foram utilizados frascos com capacidade de $30 \mathrm{~mL}$ contendo $10 \mathrm{~mL}$ de meio de cultura, vedados com tampa plástica.

\section{Enraizamento in vitro}

Brotações provenientes da fase de multiplicação, após cinco subcultivos, foram seccionadas em microestacas de $1,0 \mathrm{~cm}$, e cultivadas em meio de cultura MS, suplementado com $100 \mathrm{mg} \mathrm{L}^{-1}$ de mio-inositol, $30 \mathrm{~g} \mathrm{~L}^{-1}$ de sacarose, $6 \mathrm{~g} \mathrm{~L}^{-1}$ de ágar Vetec $^{\circledR}$. Os seguintes tratamentos foram aplicados: 0,$5 ; 1,0$ e 2,0 $\mu \mathrm{M}$ de AIB (ácido indolbutírico) e a ausência do regulador, utilizada como testemunha. $\mathrm{O}$ pH foi ajustado para 5,8 antes da autoclavagem. Foram inoculadas cinco microestacas por frasco com capacidade de $250 \mathrm{~mL}$ contendo $20 \mathrm{~mL}$ de meio de cultura. As culturas foram mantidas em sala climatizada, com temperatura de $25 \pm 2{ }^{\circ} \mathrm{C}$, densidade de fluxo de fótons de $40 \mu \mathrm{mol} \mathrm{m} \mathrm{m}^{-2} \mathrm{~s}^{-1} \mathrm{e}$ fotoperíodo de 16 horas. Após 30 dias de cultivo foram avaliadas as variáveis número de raízes, comprimento das raízes $(\mathrm{cm})$ e porcentagem de enraizamento. $\mathrm{O}$ delineamento experimental foi inteiramente casualizado, com quatro repetições e 10 microestacas por repetição.

\section{Enraizamento ex vitro}

Microestacas provenientes da fase de multiplicação in vitro foram seccionadas com 2,0 $\mathrm{cm}$ ou 4,0 cm de comprimento, e a base foi imersa por 10 segundos em solução de ácido indolbutírico (AIB) diluído em etanol 50\%. As concentrações de AIB utilizadas foram 2,5; 5,0 e 10,0 mM e a ausência do regulador, utilizada como testemunha. As microestacas foram transplantadas em tubetes plásticos de $53 \mathrm{~cm}^{3}$ contendo substrato comercial Plantmax ${ }^{\circledR}$ e mantidas em câmara de nebulização intermitente, com intervalo de rega das 8 às $17 \mathrm{~h}$, com irrigação de $15 \mathrm{~s}$ a cada $15 \mathrm{~min}$; das 17 às 23 $\mathrm{h}$, com irrigação de $15 \mathrm{~s}$ a cada uma hora e; das 23 às $8 \mathrm{~h}$, com irrigação de $15 \mathrm{~s}$ a cada $3 \mathrm{~h}$, por 15 dias e em seguida foram levadas para casa-devegetação, onde permaneceram por mais 15 dias, com regas realizadas manualmente.

$\mathrm{O}$ delineamento experimental foi inteiramente casualizado em esquema fatorial 2 x 4 (dois comprimentos de microestacas e quatro concentrações de AIB), com quatro repetições e 10 explantes por repetição.

\section{Análise estatística}

Os dados foram submetidos à análise de variância ( $\mathrm{p} \leq 0,05)$ e avaliados pela análise de regressão. Dados em porcentagem foram transformados em arc sen $\sqrt{x} / 100$. Para análise dos dados foi utilizado o programa ASSISTAT.

\section{Histologia}

Após quatro semanas de enraizamento ex vitro, a base das microestacas foi seccionada e fixada em FAA [formaldeído (40\%): ácido acético glacial: etanol (50\%), a 5:5:90 v/v/v]. Esses materiais foram destinados à preparação de lâminas permanentes, sendo incluídos em 2hidroxietilmeta-acrilato (historresina-Leica), segundo a técnica de Feder e O’Brien (1968) e as indicações do fabricante. Os blocos foram seccionados em micrótomo de rotação; os cortes foram obtidos com 7,0 $\mu \mathrm{m}$ de espessura e corados com azul de toluidina (Feder e O'Brien, 1968). As lâminas foram montadas com resina sintética $\left(\right.$ Permalte $^{\circledR}$ ). As fotomicrografias foram obtidas em microscópio Zeiss com câmera digital Sony Cyber-shot P200 ${ }^{\circledR}$ acoplada.

\section{RESULTADO E DISCUSSÃO}

Para o enraizamento in vitro das microestacas a suplementação de AIB no meio de cultura apresentou efeito significativo para o número de raízes e porcentagem de enraizamento, mas para o comprimento das raízes não houve efeito significativo (Tabela 1).

Tabela 1. Resumo da análise de variância para o número de raízes, comprimento das raízes (cm) e porcentagem de enraizamento de L. angustifolia cv. Provence Blue, em relação à concentração de ácido indolbutírico (AIB) no enraizamento in vitro, após 30 dias do tratamento.

\begin{tabular}{ccccc}
\hline \multirow{2}{*}{ Fontes de Variação } & \multirow{2}{*}{ G.L. } & \multicolumn{3}{c}{ Quadrado Médio } \\
\cline { 3 - 5 } & & Número de raízes & Comprimento das raízes & Enraizamento (\%) \\
\hline Concentração de AIB & 3 & $2,986^{* *}$ & $0,0758^{\text {ns }}$ & $182,969^{* *}$ \\
Resíduo & 10 & 0,057 & 0,0417 & 9,579 \\
Total & 13 & - & - & - \\
\hline C.V. $(\%)$ & & 17,94 & 38,27 & 8,68 \\
\hline
\end{tabular}

** significativo a $1 \%$ de probabilidade pelo teste de F. ns - não significativo pelo teste $\mathrm{F}$. 
O efeito das concentrações de AIB sobre o número de raízes induzidas in vitro pode ser observado pela análise de regressão linear apresentada na Figura 1A. Houve decréscimo do número de raízes principais, não sendo observadas raízes nas microestacas cultivadas em meio de cultura com 2,0 $\mu \mathrm{M}$ de AIB. A ausência da auxina no meio de cultura resultou em maior número de raízes principais por microestacas. Assim como o número de raízes, a variável comprimento das raízes também apresentou comportamento linear decrescente, segundo a análise de regressão (Figura 1B). Para algumas espécies as auxinas estimulam a indução do enraizamento, porém, inibem as fases de iniciação e alongamento, apresentando dessa forma efeito negativo no desenvolvimento das raízes adventícias (Hartmann e Kester, 2002).

A porcentagem de microestacas enraizadas in vitro foi baixa, apresentando valores menores de 50\%, no controle, e de $30 \%$ nas concentrações de 0,5 $\mu \mathrm{M}$ e $1,0 \mu \mathrm{M}$ de AIB. Não houve microestacas enraizadas na concentração de $2,0 \mu \mathrm{M}$ de AIB (Figura 1C). $\mathrm{O}$ enraizamento in vitro de $L$. pedunculata ocorreu sem a adição de auxina no meio (Zuzarte et al., 2010). De Bona et al. (2011), observaram taxas de enraizamento in vitro de $L$. angustifolia inferiores a 70\%, ao utilizarem ácido naftaleno acético (ANA) no meio de enraizamento. Os resultados encontrados no presente estudo evidenciam a ineficiência do enraizamento in vitro de $L$. angustifolia, quando o meio de cultura é suplementado com AIB.

\section{A}

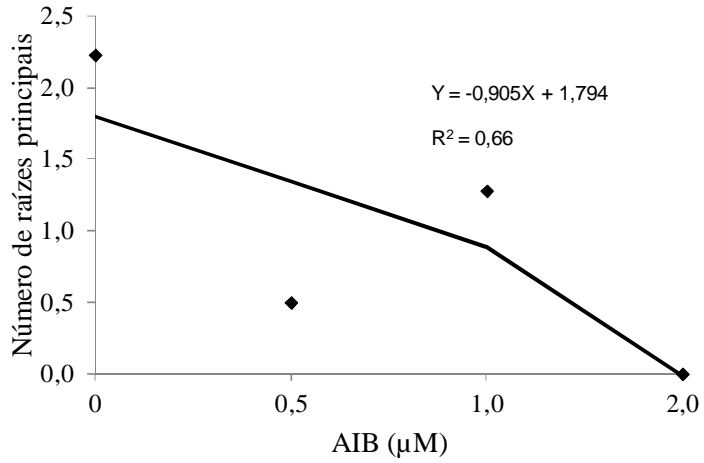

B

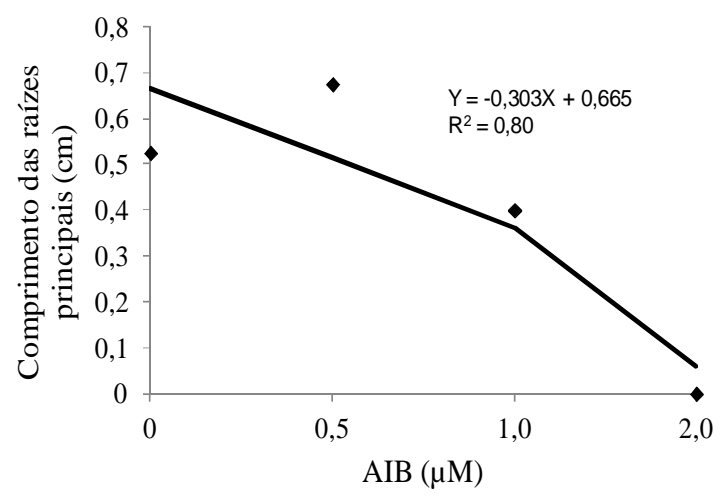

C

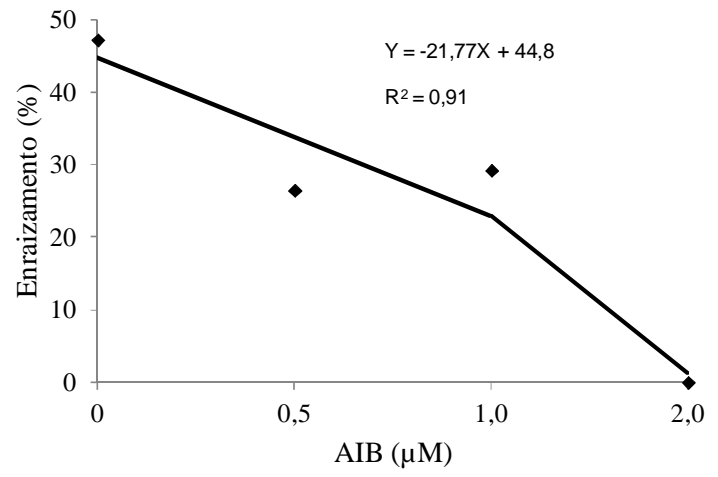

Figura 1 - Efeito de diferentes concentrações de ácido indolbutírico (AIB) no enraizamento in vitro de microestacas de $L$. angustifolia (A) Número de raízes principais, (B) Comprimento das raízes (cm), (C) Porcentagem de enraizamento, após 30 dias do tratamento. Onde: $\mathrm{X}=$ concentração de $\mathrm{AIB}, \mathrm{Y}=$ variável resposta.

A análise de variância (Tabela 2) apresentou diferenças significativas, pelo teste $\mathrm{F}$ para $\mathrm{o}$ número de raízes, porcentagem de enraizamento e porcentagem de sobrevivência em relação ao tamanho inicial da microestaca e concentração de AIB. Para o comprimento das raízes, apenas as concentrações de AIB apresentaram efeito significativo sobre esta variável. 
Tabela 2. Resumo da análise de variância para o número de raízes, comprimento das raízes $(\mathrm{cm})$, porcentagem de enraizamento e porcentagem de sobrevivência de L. angustifolia cv. Provence Blue, em relação ao tamanho inicial da microestaca e concentração de ácido indolbutírico (AIB), após 30 dias do tratamento.

\begin{tabular}{cccccc}
\hline \multirow{2}{*}{ Fontes de Variação } & G.L. & \multicolumn{4}{c}{ Quadrado Médio } \\
\cline { 3 - 6 } & & $\begin{array}{c}\text { Número de } \\
\text { raízes }\end{array}$ & $\begin{array}{c}\text { Comprimento } \\
\text { das raízes }\end{array}$ & $\begin{array}{c}\text { Enraizamento } \\
(\%)\end{array}$ & $\begin{array}{c}\text { Sobrevivência } \\
(\%)\end{array}$ \\
\hline Tamanho inicial da & 1 & $47,05^{* *}$ & $0,75^{\text {ns }}$ & $0,16^{* *}$ & $0,31^{* *}$ \\
microestaca (A) & 3 & $81,00^{* *}$ & $21,62^{* *}$ & $0,45^{* *}$ & $0,46^{* *}$ \\
Concentração de AIB (B) & 3 & $5,73^{* *}$ & $3,16^{\text {ns }}$ & $0,10^{* *}$ & $0,08^{* *}$ \\
A x B & 24 & 0,64 & 2,35 & 0,01 & $0,01^{* *}$ \\
Resíduo & 31 & - & - & - & - \\
Total & & 12,58 & 23,15 & 12,31 & 11,75 \\
\hline C.V. (\%) & &
\end{tabular}

** significativo a $1 \%$ de probabilidade pelo teste de $\mathrm{F}$. ns - não significativo pelo teste $\mathrm{F}$.

O melhor efeito do AIB em relação ao número de raízes por microestaca foi observado nas microestacas de $4,0 \mathrm{~cm}$ tratadas com $10 \mathrm{mM}$ de AIB, obtendo-se aproximadamente 12 raízes por microestaca em 30 dias. As microestacas não tratadas com AIB (testemunha) apresentaram o menor número de raízes por microestaca, independentemente do tamanho. No entanto, para todas as concentrações de AIB as microestacas de $4,0 \mathrm{~cm}$ apresentaram os maiores valores para $\mathrm{O}$ número de raízes (Figura 2A). A aplicação exógena de auxinas em estacas estimula a formação de raízes adventícias, aumentando o número de raízes formadas (Brondani et al., 2012), considerando que esse resultado também foi observado em microestacas de L. angustifolia cv. Provence Blue.

Apesar das microestacas não tratadas com AIB terem apresentado o menor número de raízes por microestaca (Figura 2A), estas desenvolveram maior comprimento das raízes principais $(8,8 \mathrm{~cm})$. $\mathrm{O}$ tamanho inicial das microestacas não teve efeito sobre esta variável, segundo o teste $\mathrm{F}$ da análise de variância (Tabela 2). Houve uma tendência de redução do comprimento das raízes principais, com o aumento das concentrações de AIB, sendo obtidos $8,8 \mathrm{~cm}$ na ausência da auxina e $4,9 \mathrm{~cm}$ na concentração de $10 \mathrm{mM}$ (Figura 2B).

Microestacas de 2,0 $\mathrm{cm}$ de comprimento tratadas com $10 \mathrm{mM}$ de AIB apresentaram a menor porcentagem de enraizamento (15\%), em relação aos demais tratamentos (Figura 2C). Os resultados demonstram que a concentração mais elevada de AIB $(10 \mathrm{mM})$ inibiu o desenvolvimento de raízes das microestacas de $2,0 \mathrm{~cm}$ e $4,0 \mathrm{~cm}$ de comprimento. A maior porcentagem de enraizamento foi obtida com a concentração de 5
$\mathrm{mM}$ de AIB, para microestacas de 2,0 $\mathrm{cm}$ e 4,0 cm de comprimento, obtendo-se $78 \%$ e $85 \%$ de enraizamento respectivamente (Figura 2C). Machado et al. (2011), encontraram resultados semelhantes com a aplicação de AIB em microestacas da mesma espécie, utilizando microestacas de $4,0 \mathrm{~cm}$, porém a aplicação do regulador foi realizada via talco. Isso demonstra que as duas formas de aplicação de AIB, talco e solução, podem ser utilizadas no enraizamento das microestacas.

As respostas encontradas para a porcentagem de enraizamento das microestacas de $4,0 \mathrm{~cm}$ de comprimento pode ser devido a maior reserva de carboidratos, em relação às microestacas de $2,0 \mathrm{~cm}$ de comprimento. Porém, um estudo comparativo é necessário para verificar se a forma de aplicação de AIB influencia respostas diferenciadas. A formação de raízes adventícias é um processo que exige elevada energia, por envolver a divisão celular, na qual as células predeterminadas alteram a rota morfogenética para formar os primórdios radiciais (Aeschabacher et al., 1994; Brondani et al., 2012). E como demonstrado por Haq et al. (2009), as reservas de carboidratos nas microestacas de Olea europaea constituem a principal fonte de energia para a iniciação dos primórdios radiciais.

Assim como observado por $\mathrm{Xu}$ et al. (2008), onde microestacas de Malus zumi mais longas (3,5 - 5,0 $\mathrm{cm}$ ), apresentaram maior porcentagem de enraizamento ex vitro (>70\%), os resultados encontrados no presente trabalho indicam que o tamanho inicial das microestacas é um fator que afeta a produção ex vitro do sistema radicial de $L$. angustifolia. 
A porcentagem de sobrevivência das plantas, provenientes de microestacas de $2,0 \mathrm{~cm}$ de comprimento tratadas com diferentes concentrações de AIB, variou de $15 \%$ a $83 \%$, enquanto aquelas provenientes de microestacas de $4,0 \mathrm{~cm}$ apresentaram sobrevivência variando de $53 \%$ a $88 \%$. A concentração de $10 \mathrm{mM}$ de AIB reduziu a porcentagem de sobrevivência, para ambos os tamanhos de microestacas investigados. Para todas as concentrações de AIB testadas a utilização de microestacas de $4,0 \mathrm{~cm}$ de comprimento resultou em maior sobrevivência das plantas, quando comparada com as microestacas de 2,0 cm de comprimento (Figura 2D).

Tanto para a porcentagem de enraizamento, quanto para a porcentagem de sobrevivência das microestacas, observa-se uma tendência de redução a partir de concentrações superores a 5 $\mathrm{mM}$ de AIB (Figura 2C, D), indicando que a aplicação de AIB acima de $5 \mathrm{mM}$ não é recomendada para o enraizamento ex vitro de $L$. angustifolia.

$\mathbf{A}$

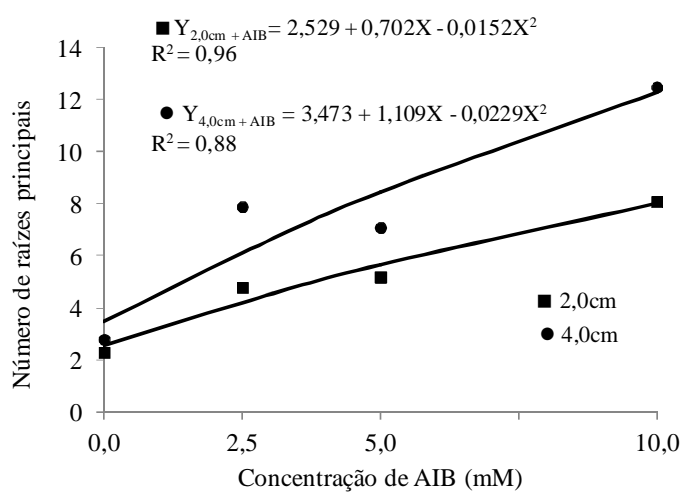

B

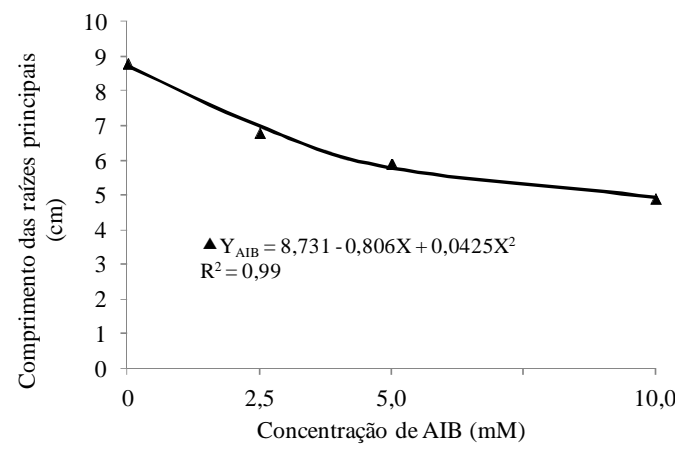

C

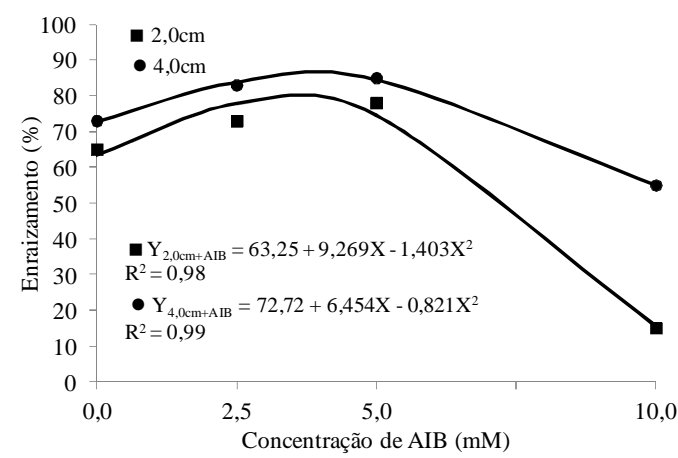

D

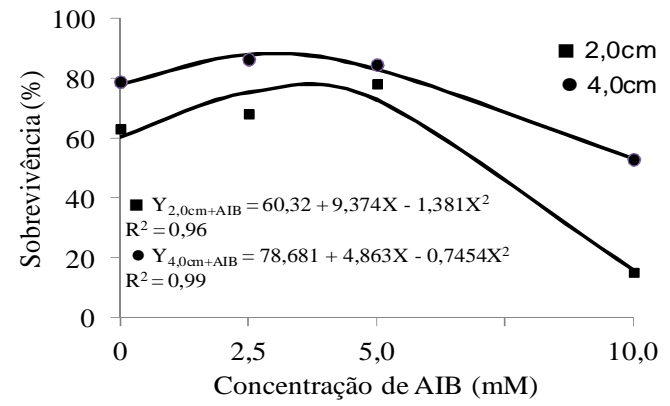

Figura 2 - Efeito de diferentes concentrações de ácido indolbutírico (AIB) em microestacas de L. angustifolia cv. Provence Blue com 2,0 cm e 4,0 cm de comprimento. (A) Número de raízes principais, (B) Comprimento das raízes $(\mathrm{cm})$, (C) Porcentagem de enraizamento, (D) Porcentagem de sobrevivência das plantas após 30 dias da aplicação do tratamento. Onde: $\mathrm{X}=$ concentração de AIB e Y = variável resposta.

O enraizamento ex vitro possibilita a obtenção de plantas com maior capacidade de emissão de raízes e maior velocidade de crescimento inicial, tendo em vista que as raízes desenvolvidas in vitro podem não ser funcionais e morrem após a transferência para aclimatização, sendo necessário induzir novas raízes após a passagem para as condições ex vitro (Deberg e Maene, 1981). Além disso, a aplicação de regulador vegetal e o comprimento das microestacas interferiram no enraizamento de L. angustifolia cv. Provence Blue (Figura 2A, B).

Microestacas tratadas e não tratadas com AIB foram submetidas à cortes histológicos para se determinar a origem das raízes, uma vez que raízes adventícias podem ser originadas de células parenquimáticas vivas, calos, câmbio, raio vascular ou medular, floema, córtex, lenticelas ou canais resiníferos (Appezzato-da-Glória \& Carmello-Guerreiro, 2003). No corte transversal realizado na região basal das microestacas tratadas 
com AIB, com quatro semanas em casa-devegetação, verificou-se a formação endógena das raízes adventícias a partir do câmbio vascular, não sendo observada a formação de calo na região interna da microestaca (Figuras 3C e 3D). Avaliando as plantas de Siratia grovenorii obtidas pelo método de enraizamento ex vitro, Yan et al. (2010) também observaram a ausência de calos na base das microestacas utilizando AIB. Esse resultado mostra a eficiência da formação das raízes adventícias a partir de microestacas, em ambiente ex vitro, pois a formação de calo dificulta a conexão do sistema vascular entre caule e raiz (George et al., 2008). Dessa forma, a fase de enraizamento ex vitro de $L$. angustifolia apresentase como uma importante etapa no processo de micropropagação.

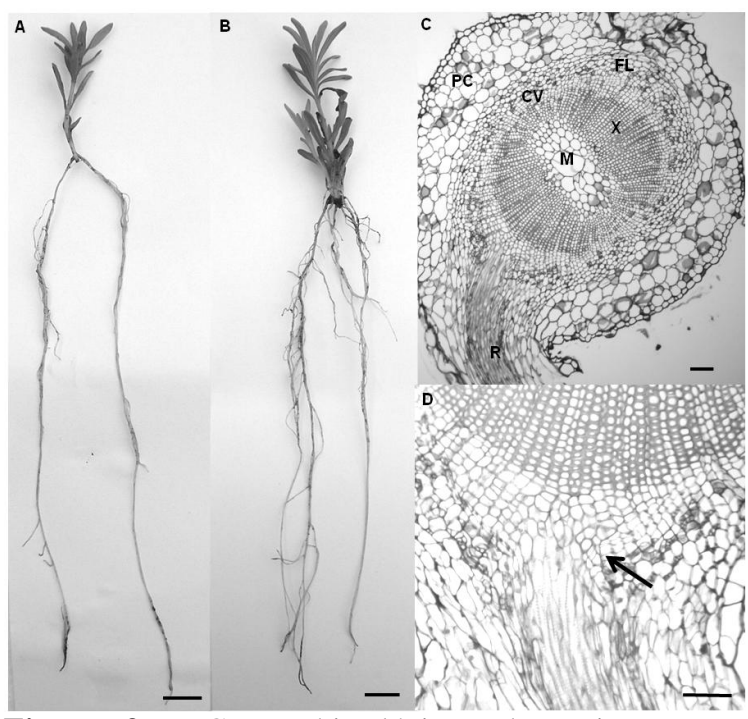

Figura 3 - Cortes histológicos das microestacas enraizadas e micrografias de caule de L. angustifolia cv. Provence Blue, após quatro semanas de cultivo. (A) Detalhe da microestaca de $2,0 \mathrm{~cm}$ de comprimento inicial não tratada com AIB. (B) Detalhe da microestaca de 4,0 cm de comprimento inicial tratada com 5,0 mM de AIB. (C) Corte transversal da base da microestaca enraizada ex vitro. (D) Corte transversal da base da microestaca enraizada ex vitro, evidenciando a região de conexão entre a raiz adventícia e o câmbio vasculas (seta). Medula (M), raiz (R), câmbio vascular (CV), parênquima cortical (PC), xilema (X), floema (FL). Barras A e B = 1,0 cm. Barras C e D = 500 $\mu \mathrm{m}$.

\section{CONCLUSÃO}

O tamanho inicial das microestacas e a concentração do ácido indolbutírico influenciaram o enraizamento adventício das microestacas de Lavandula angustifolia.
$\mathrm{O}$ enraizamento ex vitro com a utilização de microestacas de $4,0 \mathrm{~cm}$ de comprimento proporcionou maior enraizamento e sobrevivência das microestacas.

A concentração de $5,0 \mathrm{mM}$ de AIB aplicada via solução na base das microestacas foi eficiente para a indução de raízes adventícias em microestacas, de $2,0 \mathrm{~cm}$ e $4,0 \mathrm{~cm}$ de comprimento, bem como favoreceu a sobrevivência das plantas de Lavandula angustifolia.

\section{REFERÊNCIA}

AESCHABACHER, R. A.; SCHIEFELBEIN, J. W.; BENFEY, P. N. The genetic and molecular basis of root development. Annual Review of Plant Physiology and Plant Molecular Biology, v.45, n.1, p. 25-45, 1994.

APPEZZATO-DA-GLÓRIA, B.; CARMELLOGUERREIRO, S. M. (Eds.). Anatomia Vegetal. Viçosa: Editora UFV. 438. 2003

BRONDANI, G. E.; ONDAS, H. W. W.; BACCARIN, F. J. B.; GONÇALVES, A. N.; ALMEIDA, M. Micropropagation of Eucalyptus benthamii to form a clonal micro-garden. In Vitro Cellular \& Developmental Biology - Plant, v.48, p.478-487, 2012.

BRONDANI, G. E.; HOFFMANN, J. M. E.; GOLÇALVES, A. N.; ALMEIDA, M. Determinação do teor de carboidratos em minicepas de Eucalyptus benthamii. Journal of Biotechnology and Biodiversity, v.3, n.1, p.5160, 2012.

DEBERG, P. C. e MAENE, L. J. A. A scheme for commercial propagation for ornamental plants by tissue culture. Scientia Horticulturae, v.14, n.4, p. 335-345, 1981.

DE BONA, C. M.; BIASI, L. A.; DESCHAMPS, C.; REINHART, V. In vitro rooting of Lavandula angustifolia. Revista Brasileira de Agrociência, v. 17, n. 3-4, p.401-404, 2011.

FEDER, N.; O'BRIEN, T. P. Plant microtechnique: some principles and new methods. American Journal of Botany, v.55, n.1, p.123-142, 1968.

FLORES, G.; BLANCH, G. P.; RUIZ DEL CASTILLO, M. L.; HERRAIZ, M. Enantiomeric 
composition studies in Lavandula species using supercritical fluids. Journal of Separation Science, v.28, n.17, p.2333-2338, 2005.

GEORGE, E. F.; HALL, M. A.; DE KLERK, G. J. Plant propagation by tissue culture. 3. Ed. Dordrecht: Springer. P. 473, 2008.

GEORGE, E. F. e SHERRINGTON, P. D. Plant propagation by tissue culture, handbook and Directory of Commercial Laboratories. Everley: Exegetics. P. 709, 1984.

GHELARDINI, C.; GALEOTTI, N.; SALVATORE, G.; MAZZANTI, G. Local anaesthetic activity of the essential oil of Lavandula angustifolia. Planta Medica, v.65, n.8, p.700-703, 1999.

GROUT, B. W. W.; ASTON, M. J. Transplanting of cauliflower plants regenerated from meristem culture. Water loss and water transfer related to changes in leaf wax and to xylem regeneration. Horticultural Research, v.17, n.1, p.1-7, 1977.

HAQ, I. U.; AHMAD, T.; HAFIZ, I. A.; ABBASI, $\mathrm{N}$. A. Influence of microcutting sizes and IBA concentrations on in vitro rooting of olive $\mathrm{cv}$. 'Dolce Agogia'. Pakistan Journal Botany, v.41, n.3, p.1213-1222, 2009.

HARTMANN, H. T.; KESTER, D. E. Plant propagation: principles and pratice. 7 . ed. New Jersey: Prentice Hall. p. 880, 2002.

KARHU, S. T. Rooting of blue honeysuckle microshoots. Plant Cell, Tissue and Organ Culture, v.48, n.3, p.153-159, 1997.

KREIS, P.; MOSANDL, A. Chiral compounds of essential oils. Part XI. Simultaneous stereoanalysis of lavandula oil constituents. Flavour and Fragrance Journal, v.7, n.4, p.187-193, 1992.

MACHADO, M. P.; SANTOS, G. D.; DESCHAMPS, C.; BIASI, L. A. Enraizamento de microestacas de Lavandula angustifolia. Ciência Rural, v.41, n.5, p.767-772, 2011.

MARTIN, K. P. Rapid in vitro multiplication and ex vitro rooting of Rotula aquatica Lour., a rare rhoeophytic woody medicinal plant. Plant Cell Reports, v.21, n.5, p.415-420, 2003a.
MARTIN, K. P.; BENNA, M. R.; JOSEPH, D. High frequency axillary bud multiplication and $e x$ vitro rooting of Wedelia chinensis (Osbeck) Merr. - A medicinal plant. Indian Journal Experimental Biology, v.41, n.3, p.262-266, $2003 b$.

MURASHIGE, T.; SKOOG, F. A revised medium for rapid growth and bioassays with tobacco tissue cultures. Physiologia Plantarum, v.15, n.3, p.473-497, 1962.

PIERIK, R. L. M. Cultivo in vitro de las plantas superiores. 3. Ed. Madrid: Ediciones MundiPrensa. 1990.

SCHUCH, M. W.; ROSSI, A. de; DAMIANI, C. R.; SOARES, G. C. AIB e substrato na produção de mudas de mirtilo cv. "Climax" através de microestaquia. Ciência Rural, v.37, n.5, p.14461449, 2007.

SUGAWARA, Y.; HARA, C.; TAMURA, K.; FUJII, T.; NAKAMURA, K.; MASUJIMA, T.; AOKI, T. Sedative effect on humans of inhalation of essential oil of linalool: sensory evaluation and physiological measurements using optically active linalools. Analytica Chimica Acta, v. 365, n.1, p.293-299, 1998.

SUNANDAKUMARI, C.; MANTIN, K. P.; CHITHRA, M.; SINI, S.; MADHUSOODANAN, P. V. Rapid axillary bud proliferation and ex vitro rooting of herbal spice, Mentha piperita L. Indian Journal of Biotechnology, v.3, n.1, p.108-112, 2004.

UPSON, T. The taxonomy of the genus Lavandula L. In: LIS-BALCHIN, M. The Genus Lavandula. London: Taylor and Francis. P. 268, 2002.

YAN, H.; LIANG, C.; YANG, L. LI, Y. In vitro and ex vitro rooting of Siratia grosvenorii, a traditional medicinal plant. Acta Physiologiae Plantarum, v.32, n.1, p.115-120, 2010.

XAVIER, A.; ANDRADE, H. B.; OLIVEIRA, M. L.; WEINDLING, I. Desempenho do enraizamento de microestacas e miniestacas de clones híbridos de Eucalyptus grandis. Revista Árvore, v.25, n.4, p. 403-411, 2001. 
XU, J.; WANG, Y.; ZHANG, Y.; CHAI, T. Rapid in vitro multiplication and ex vitro rooting of Malus zumi (Matsumura) Rehd. Acta Physiologiae Plantarum, v.30, n.1, p.129-132, 2008.

ZUZARTE, M. R.; DINIS, A. M.; CAVALEIRO, C.; SAlGUEIRO, L. R.; CANHOTO, J. M. Trichomes, essential oils and in vitro propagation of Lavandula pedunculata (Lamiaceae). Industrial Crops and Products, v.32, p.580-587, 2010.

Recebido: 08/10/2012

Received: 11/08/2012

Aprovado: 02/02/2013 Approved: 02/02/2013 